HNF-29820

Revision 0

\title{
Technical Justification for Choosing Propane as a Calibration Agent for Total Flammable Volatile Organic Compound Determinations
}

Prepared for the U.S. Department of Energy

Assistant Secretary for Environmental Management

Project Hanford Management Contractor for the

U.S. Department of Energy under Contract DE-AC06-96RL13200

\section{$=\ln 0$}

P.O. Box 1000

Richland, Washington 
HNF-29820

Revision 0

EDC \#: HNF-EDC-06-29821

\section{Technical Justification for Choosing Propane as a Calibration Agent for Total Flammable Volatile Organic Compound Determinations}

Document Type: TR

J. G. Douglas

Fluor Government Group

Date Published

July 2006

Prepared for the U.S. Department of Energy

Assistant Secretary for Environmental Management

Project Hanford Management Contractor for the

U.S. Department of Energy under Contract DE-AC06-96RL13200

\section{FLUOR}

P.O. Box 1000

Richland, Washington

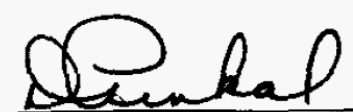

Release Approval $\frac{7 / 6 / 06}{\text { Date }}$

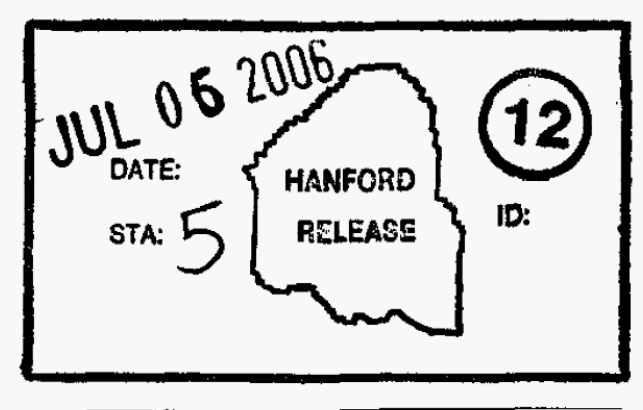

Release Stamp

Approved for Public Release;

Further Dissemination Unlimited 
HNF-29820

Revision 0

TRADEMARK DISCLAIMER

Reference herein to any specific commercial product, process,

or service by trade name, trademark, manufacturer, or

otherwise, does not necessarily constitute or imply its

endorsement, recommendation, or favoring by the United

States Government or any agency thereof or its contractors or subcontractors.

This report has been reproduced from the best available copy.

Printed in the United States of America

Total Pages: $\quad 18$ 


\title{
HNF-29820 Rev. 0
}

\section{Technical Justification for Choosing Propane as a Calibration Agent for Total Flammable Volatile Organic Compound Determinations}

\author{
J. G. Douglas \\ Waste Sampling and Characterization Facility \\ July 6, 2006
}

\subsection{Introduction}

This document presents the technical justification for choosing and using propane as a calibration standard for estimating total flammable volatile organic compounds (VOCs) in an air matrix. A propane-in-nitrogen standard was selected based on a number of criteria: (1) has an analytical response similar to the VOCs of interest, (2) can be made with known accuracy and traceability, (3) is available with good purity, (4) has a matrix similar to the sample matrix, (5) is stable during storage and use, (6) is relatively non-hazardous, and (7) is a recognized standard for similar analytical applications.

The Waste Retrieval Project (WRP) desires a fast, reliable, and inexpensive method for screening the flammable VOC content in the vapor-phase headspace of waste containers.

Table 1 lists the flammable VOCs of interest to the WRP. The current method used to determine the VOC content of a container is to sample the container's headspace and submit the sample for gas chromatography - mass spectrometry (GC-MS) analysis. The driver for the VOC measurement requirement is safety: potentially flammable atmospheres in the waste containers must be allowed to diffuse prior to processing the container.

The proposed flammable VOC screening method is to inject an aliquot of the headspace sample into an argon-doped pulsed-discharge helium ionization detector (Ar-PDHID) contained within a gas chromatograph. No actual chromatography is performed; the sample is transferred directly from a sample loop to the detector through a short, inert transfer line. The peak area resulting from the injected sample is proportional to the flammable VOC content of the sample.

However, because the Ar-PDHID has different response factors for different flammable VOCs, a fundamental assumption must be made that the agent used to calibrate the detector is representative of the flammable VOCs of interest that may be in the headspace samples. At worst, we desire that calibration with the selected calibrating agent overestimate the value of the VOCs in a sample. By overestimating the VOC content of a sample, we want to minimize false negatives. A false negative is defined as incorrectly estimating the VOC content of the sample to be below programmatic action limits when, in fact, the sample exceeds the action limits. The disadvantage of overestimating the flammable VOC content of a sample is that additional cost may be incurred because additional sampling and GC-MS analysis may be required to confirm 


\section{HNF-29820 Rev. 0}

results over programmatic action limits. Therefore, choosing an appropriate calibration standard for the Ar-PDHID is critical to avoid false negatives and to minimize additional analytical costs.

The following summarizes the requirements for a good calibration standard:

1. Is the same as, or at least has a response similar to, the analytes of interest,

2. Is available with known accuracy, preferably traceable to some recognized standard (e.g. a National Institute of Standards and Technology standard),

3. Is available pure or with known purity,

4. Has a matrix similar of the samples to be analyzed,

5. Is stable during transportation, storage, and usage for a reasonable length of time,

6. Is relatively non-hazardous, and

7. Is a recognized calibration standard for similar applications.

Each of these points is addressed in the following sections. 


\section{HNF-29820 Rev. 0}

Table 1. Flammable Volatile Organic Compounds of Interest ${ }^{1}$

\begin{tabular}{|c|c|c|}
\hline Flammable VOC & Formula & $\begin{array}{c}\text { CAS } \\
\text { Number }\end{array}$ \\
\hline acetone & $\mathrm{C}_{3} \mathrm{H}_{6} \mathrm{O}$ & $67-64-1$ \\
\hline benzene & $\mathrm{C}_{6} \mathrm{H}_{6}$ & $71-43-2$ \\
\hline butanol & $\mathrm{C}_{4} \mathrm{H}_{10} \mathrm{O}$ & $35296-72-1$ \\
\hline carbon disulfide & $\mathrm{CS}_{2}$ & $75-15-0$ \\
\hline chlorobenzene & $\mathrm{C}_{6} \mathrm{H}_{5} \mathrm{Cl}$ & $108-90-7$ \\
\hline chloroethane (ethyl chloride) & $\mathrm{C}_{2} \mathrm{H}_{5} \mathrm{Cl}$ & $75-00-3$ \\
\hline cyclohexane & $\mathrm{C}_{6} \mathrm{H}_{12}$ & $110-82-7$ \\
\hline 1,1-dichloroethane & $\mathrm{C}_{2} \mathrm{H}_{4} \mathrm{Cl}_{2}$ & $75-34-3$ \\
\hline 1,2-dichloroethane & $\mathrm{C}_{2} \mathrm{H}_{4} \mathrm{Cl}_{2}$ & $107-06-2$ \\
\hline 1,2-dichloroethylene & $\mathrm{C}_{2} \mathrm{H}_{2} \mathrm{Cl}_{2}$ & $540-59-0$ \\
\hline 1,1-dichloroethylene & $\mathrm{C}_{2} \mathrm{H}_{2} \mathrm{Cl}_{2}$ & $75-35-4$ \\
\hline dichloromethane & $\mathrm{CH}_{2} \mathrm{Cl}_{2}$ & $75-09-2$ \\
\hline dichloropropane & $\mathrm{C}_{3} \mathrm{H}_{6} \mathrm{Cl}_{2}$ & $26638-19-7$ \\
\hline dioxane & $\mathrm{C}_{4} \mathrm{H}_{8} \mathrm{O}$ & $123-91-1$ \\
\hline ethyl benzene & $\mathrm{C}_{8} \mathrm{H}_{10}$ & $100-41-4$ \\
\hline ethyl ether (oxybisethane) & $\mathrm{C}_{4} \mathrm{H}_{10} \mathrm{O}$ & $60-29-7$ \\
\hline isopropyl alcohol (2-propanol) & $\mathrm{C}_{3} \mathrm{H}_{8} \mathrm{O}$ & $67-63-0$ \\
\hline methanol & $\mathrm{CH}_{4} \mathrm{O}$ & $67-56-1$ \\
\hline methyl chloride (chloromethane) & $\mathrm{CH}_{3} \mathrm{Cl}$ & $74-87-3$ \\
\hline methyl ethyl ketone & $\mathrm{C}_{4} \mathrm{H}_{8} \mathrm{O}$ & $78-93-3$ \\
\hline methyl isobutyl ketone & $\mathrm{C}_{6} \mathrm{H}_{12} \mathrm{O}$ & $108-10-1$ \\
\hline 1,1,1-trichloroethane & $\mathrm{C}_{2} \mathrm{H}_{3} \mathrm{Cl}_{3}$ & $71-55-6$ \\
\hline trichloroethylene & $\mathrm{C}_{2} \mathrm{HCl}_{3}$ & $79-01-6$ \\
\hline 1,2,4-trimethylbenzene & $\mathrm{C}_{9} \mathrm{H}_{12}$ & $95-63-6$ \\
\hline toluene & $\mathrm{C}_{7} \mathrm{H}_{8}$ & $108-88-3$ \\
\hline xylene & $\mathrm{C}_{8} \mathrm{H}_{10}$ & $1330-20-7$ \\
\hline propane & $\mathrm{C}_{3} \mathrm{H}_{8}$ & $74-98-6$ \\
\hline
\end{tabular}

Notes:

${ }^{1}$ Information in this table was provided by the Waste Retrieval Project.

CAS $=$ Chemical Abstracts Service

$\mathrm{VOC}=$ volatile organic compound 


\section{HNF-29820 Rev. 0}

\subsection{Calibration Standard Should Be Representative of the Analytes of Interest}

Typically, an analytical calibration is performed with the same species as that to be measured in actual samples. In this case, we propose calibrating the instrument with a single species while the samples may contain different or multiple species. So the question becomes how can we be certain we will obtain results that are actually representative of the sample? To answer this question, we need to compare the detector's response factors for the VOCs of interest to the response factor of the calibration species.

Response factors for the compounds in Table 1 for the Ar-PDHID are not readily available. However, the response of the Ar-PDHID is similar to that of an 11.7 electron-volt (eV) photoionization detector (PID) (Gremaud et al. 1996, Wentworth et al. 1996). The response of the Ar-PDHID is similar to the $11.7 \mathrm{eV}$ PID because both detectors produce ionizing photons of the same energy. Vendors of hand-held, PID-based, industrial-hygiene field instruments have published the equivalent of response factors for their instruments. Table 2 lists the VOCs of Table 1 and contains correction factors for an $11.7 \mathrm{eV}$ PID published by RAE Systems, Inc. (RAE Systems, Inc. 2006). Because the Ar-PDHID responds similarly to the $11.7 \mathrm{eV}$ PID instrument, we can use the data in Table 2 to predict how the Ar-PDHID will respond to the VOCs of interest when calibrated with propane.

The correction factors in column 2 of Table 2 are defined as:

$$
\begin{aligned}
& \text { correction factor }=\text { actual concentration } / \text { observed concentration } \\
& \text { actual concentration }=\text { observed concentration } x \text { correction factor }
\end{aligned}
$$

Correction factors arise because the hand-held PID instrument is typically calibrated with isobutylene, and the PID responds somewhat differently to VOCs other than the calibration species. If the industrial hygienist knows what VOC is being measured, then the concentration of that VOC may be estimated by multiplying the instrument readout by the associated correction factor for the VOC. 
HNF-29820 Rev. 0

Table 2. Typical Correction Factors for $11.7 \mathrm{eV}$ Photoionization Detector ${ }^{1}$

\begin{tabular}{|c|c|c|}
\hline Flammable VOC & Correction Factor $^{2}$ & $\begin{array}{c}\text { Normalized to } \\
\text { Propane }^{3}\end{array}$ \\
\hline acetone & 1.4 & 0.78 \\
\hline benzene & 0.6 & 0.33 \\
\hline butanol & 1.4 & 0.78 \\
\hline carbon disulfide & 0.44 & 0.24 \\
\hline chlorobenzene & 0.39 & 0.22 \\
\hline chloroethane & 1.1 & 0.61 \\
\hline cyclohexane & 0.64 & 0.36 \\
\hline 1,1-dichloroethane & $<0.89^{4}$ & $<0.49$ \\
\hline 1,2-dichloroethane & 0.6 & 0.33 \\
\hline 1,2-dichloroethylene & $0.34^{5}$ & 0.19 \\
\hline 1,1-dichloroethylene & 0.8 & 0.44 \\
\hline dichloromethane (methylene chloride) & 0.89 & 0.49 \\
\hline dichloropropane & $0.7^{6}$ & 0.39 \\
\hline dioxane & $1.0^{4}$ & 0.6 \\
\hline ethyl benzene & 0.51 & 0.28 \\
\hline ethyl ether (oxybisethane) & $0.9^{4}$ & 0.5 \\
\hline isopropyl alcohol & 2.7 & 1.5 \\
\hline methanol & 2.5 & 1.4 \\
\hline methyl chloride (chloromethane) & 0.74 & 0.41 \\
\hline methyl ethyl ketone & 1.1 & 0.61 \\
\hline methyl isobutyl ketone & 0.6 & 0.33 \\
\hline 1,1,1-trichloroethane & 1.0 & 0.56 \\
\hline trichloroethylene & 0.43 & 0.24 \\
\hline 1,2,4-trimethylbenzene & $0.3^{4}$ & 0.17 \\
\hline toluene & 0.51 & 0.28 \\
\hline xylene & $0.40^{7}$ & 0.22 \\
\hline propane & 1.8 & 1.0 \\
\hline \multicolumn{3}{|l|}{ Other VOC } \\
\hline carbon tetrachloride & 1.7 & 0.94 \\
\hline
\end{tabular}




\title{
HNF-29820 Rev. 0
}

\section{Table 2. Typical Correction Factors for $11.7 \mathrm{eV}$ Photoionization Detector ${ }^{1}$}

\author{
Notes: \\ ${ }^{1}$ Source: RAE Systems Inc. 2006. \\ ${ }^{2}$ Correction factors are for an instrument calibrated with isobutylene. These correction factors were typically \\ measured with the compound at 50 to $100 \mathrm{ppmV}$ in dry air at room temperature. The correction factors may vary \\ at concentrations greater than $1000 \mathrm{ppmV}$. \\ ${ }^{3}$ Computed by dividing the correction factor for each compound by the correction factor for propane. \\ ${ }^{4}$ Estimated value; see Appendix A. \\ ${ }^{5}$ Value is for trans-1,2-dichloroethylene. \\ ${ }^{6}$ Value is for 1,2-dichloropropane. \\ ${ }^{7}$ Value is the average of the correction factors for ortho-, meta-, and para-xylene. \\ $\mathrm{eV}=$ electron volt \\ $\mathrm{n} / \mathrm{a}=$ not available \\ ppmV $=$ parts per million by volume \\ $\mathrm{VOC}=$ volatile organic compound
}

To use the data of Table 2 to predict how the Ar-PDHID calibrated with propane might respond to the flammable VOCs of interest, the correction factors for the VOCs have been normalized to the correction factor for propane:

$$
\text { propane-normalized correction factor }=\text { correction } \text { factor }_{\text {isobutylene }} / 1.8
$$

where propane-normalized correction factor $=$ the correction factor normalized to propane (column 3 of Table 2), correction factor isobutylene $=$ the original correction factor determined with the isobutylene calibration (column 2 of Table 2), and 1.8 is the correction factor for propane based on the isobutylene calibration.

The propane-normalized correction factors may be used to predict how an Ar-PDHID calibrated with propane will respond to a given VOC. For example, if the propane-calibrated Ar-PDHID were used to analyze an air sample containing methylene chloride as the only VOC and gave a total VOC result of $1000 \mathrm{ppmV}$, then the actual concentration of methylene chloride would be:

$$
\text { actual methylene chloride concentration }=1000 \times 0.49=490 \mathrm{ppmV}
$$

where $1000=$ measured total VOC value and 0.49 is the propane-normalized correction factor for methylene chloride from column 3 of Table 2. 


\section{HNF-29820 Rev. 0}

A second example using the propane-calibrated Ar-PDHID is the analysis of an air sample containing isopropyl alcohol as the only VOC yielding a total VOC result of $1000 \mathrm{ppmV}$. The actual isopropyl alcohol concentration would be calculated as:

$$
\text { actual isopropyl alcohol concentration }=1000 \times 1.5=1500 \mathrm{ppmV}
$$

where $1000=$ measured total VOC value and 1.5 is the propane-normalized correction factor for isopropyl alcohol from column 3 of Table 2.

From these two examples, we see that if the correction factor of a measured VOC is less than the correction factor of the calibration compound, then the actual concentration of the VOC will be less than the measured concentration for that VOC. Conversely, if the correction factor of a VOC is greater than that of the calibration compound, then the VOC's actual concentration will be greater than its measured concentration. Therefore, by choosing a calibration compound with a relatively large correction factor, most of the VOCs will yield actual concentrations less than their measured concentrations. Hence, a calibration compound with a correction factor larger than most of the VOCs of interest, such as propane, will naturally tend to generate false positives rather than false negatives.

The situation is somewhat better if a mixture of VOCs is present in the sample. A weighted correction factor for a mixture of VOCs in a sample may be calculated as:

$$
\mathrm{CF}_{\text {mix }}=1 /\left(\mathrm{V}_{1} / \mathrm{CF}_{1}+\mathrm{V}_{2} / \mathrm{CF}_{2}+\mathrm{V}_{3} / \mathrm{CF}_{3}+\ldots \mathrm{V}_{\mathrm{i}} / \mathrm{CF}_{\mathrm{i}}\right)
$$

where $\mathrm{V}_{\mathrm{i}}=$ the volume fraction of vapor component $\mathrm{i}$, and $\mathrm{CF}_{\mathrm{i}}$ is the correction factor for vapor component i (RAE Systems, Inc. 2006). When a VOC with a large correction factor is mixed with VOCs with smaller correction factors, then the overall mixture correction factor will be smaller than the largest individual correction factor.

One of the limitations of the data in Table 2 is that the correction factors are valid only to $1000 \mathrm{ppmV}$. These correction factors are likely to vary at concentrations from $1000 \mathrm{ppmV}$ to $10,000 \mathrm{ppmV}$. The variation is due to the fact that the detector response is non-linear at higher concentrations, and the extent of the non-linearity varies from compound to compound. Determining how much the correction factors may vary with concentration for each compound will require considerable laboratory effort. However, one way to minimize the extent of these variations is to operate the detector in a fairly small response range so that the detector response is nearly linear within that range. A small response range may be achieved by using small sample sizes (on the order of $10 \mu \mathrm{L}$ ) and low carrier gas flow rates (less than $2 \mathrm{~mL} / \mathrm{min}$.).

The conclusion of this discussion is that by judiciously choosing the calibration agent, propane in this case, the resulting calibration will typically generate an overestimation of the VOC content of the sample. For those few analytes that may be underestimated, such as methanol and isopropyl alcohol, a conservative action limit, to be determined, will allow for any VOC concentrations that may be underestimated by the screening method. 


\section{HNF-29820 Rev. 0}

\subsection{Calibration Standard Should Be Available with Known Accuracy}

The second feature of a good standard is that it be available with known accuracy and traceable to a recognized standard such as a National Institute of Standards and Technology (NIST) standard.

The propane primary standard is proposed to be 2 vol\% propane in ultra-high purity (UHP) nitrogen. Gas vendors can typically supply such a standard with an analytical uncertainty of two percent of the nameplate value. Hence, we should expect that a commercially available propane standard should be supplied at $2.00 \pm 0.04 \mathrm{vol} \%$. This is certainly acceptable for calibration purposes and is well within the measurement error of typical gas chromatographic equipment.

Standard gases can be supplied with NIST traceability.

\subsection{Calibration Standard Should Be Available with Known Purity}

The third feature of a good standard is that it be available with known purity. Gas vendors use relatively pure starting materials to generate a calibration gas mixture, and can supply an analysis of the resulting standard gas indicating the concentration of the primary ingredients as well as any major impurities in the standard. Also, by specifying that the standard be supplied in UHP nitrogen, any minor impurities that might be associated with using an air matrix will be minimized.

\subsection{Calibration Standard Should Have a Matrix Similar to Samples}

The fourth feature of a good standard is that it be available in a matrix similar to that of the samples. In this case, the samples will be in a predominantly air matrix. The proposed $2 \mathrm{vol} \%$ propane standard will be made up in a UHP nitrogen matrix. Preliminary data indicate that the presence of oxygen has a depressive effect of about $12 \%$ on the total VOC signal. Consequently, we can expect samples in an air matrix to generate total flammable VOC values that are about $12 \%$ lower than the actual values when the instrument is calibrated with propane standards in UHP nitrogen. Except for the alcohols, this depressive effect is more than offset by the correction factors as discussed in Section 2.0.

\subsection{Calibration Standard Should Be Stable}

The fifth feature of a good standard is that it be stable during transportation, storage, and usage for a reasonable length of time. A 2 vol\% propane in nitrogen standard meets these requirements. The extremely low boiling point of propane $\left(-42.1^{\circ} \mathrm{C}\right)$ (Weast and Astle 1981) means that propane will stay in a gaseous, homogeneous state in all reasonable environmental conditions. Furthermore, most gas vendors will certify the standard value for a minimum of one year. Therefore, a 2 vol\% propane-in-nitrogen standard will be stable under most conceivable 


\section{HNF-29820 Rev. 0}

operating conditions for a reasonable period of time. If so desired, propane can also be mixed with hydrogen and methane to produce a stable multi-component standard.

\subsection{Calibration Standard Should Be Relatively Non-Hazardous}

The sixth feature of a good standard is that it be relatively non-hazardous. The lower flammability limit (LFL) of propane in air is approximately 2.1 vol\% (NIOSH 1997). While a $2 \mathrm{vol} \%$ propane standard is near the LFL, the proposed propane standard is made up in nitrogen. Hence no oxidizer is present in the standard that would support combustion of the propane.

\subsection{Calibration Standard Should Be Recognized for Similar Applications}

The final feature of a good standard is that it be recognized as a standard for similar analytical applications. An analytical method similar to the proposed total flammable VOC method is the U. S. Environmental Protection Agency's (USEPA) TO-12 air toxics method for the determination of non-methane organic compounds in ambient air (USEPA 1999). This method is used to determine non-methane VOCs in air and specifies the use of propane as the calibration standard. The TO-12 method employs a flame ionization detector (FID) rather than a PDHID, and the calibration is in terms of parts per million carbon $(\mathrm{ppmC})$ rather than total VOC in vol\%. However, the fundamental assumption in the TO- 12 method is that propane is similar enough to the VOCs being measured that calibration with propane is adequate to obtain a total carbon number for the VOCs in a sample.

\subsection{Conclusion}

The preceding discussion provides evidence that a 2 vol\% propane-in-nitrogen standard is adequate to calibrate an Ar-PDHID for determining total flammable VOCs. To account for VOCs that have a larger response factor than propane, a to-be-determined action level may be incorporated to prevent false negative results that might miss a container with a flammable VOC headspace content greater than programmatic action limits. A final comment regarding the propane-in-nitrogen standard is that it is relatively inexpensive: over the course of a year's operation of the total flammable VOC method, the cost of the standard is negligible. 


\section{HNF-29820 Rev. 0}

\subsection{References}

Gremaud, G., W. E. Wentworth, A. Zlatkis, R. Swatloski, E. C. M. Chen, S. D. Stearns, 1996, "Windowless Pulsed-Discharge Photoionization Detector: Application to Qualitative Analysis of Volatile Organic Compounds," Journal of Chromatography A, vol. 724, pp. 235 - 250.

NIOSH, 1997, NIOSH Pocket Guide to Chemical Hazards, U. S. Department of Health and Human Services Publication 97-140, p. 262.

RAE Systems, Inc., 2006, Correction Factors, Ionization Energies, and Calibration Characteristics, Technical Note TN-106, Rev. 15, http://www.raesystems.com/ raedocs/App_Tech_Notes/Tech_Notes/TN106 Correction_Factors.pdf.

USEPA, 1999, Method TO-12: Method for the Determination of Non-Methane Organic Compounds (NMOC) in Ambient Air Using Cryogenic Preconcentration and Direct Flame Ionization Detection (PDFID), U. S. Environmental Protection Agency, http://www.epa.gov/ttn/amtic/files/ambient/airtox/to-12.pdf.

Weast, R. C. and M. J. Astle, 1981, Handbook of Chemistry and Physics, $62^{\text {nd }}$ ed., p. C-463.

Wentworth, W. E., Y. Li, and S. D. Stearns, 1996, "Pulsed Discharge Photoionization Detector: Application to Analysis of Chloro Alkanes/Alkenes," Journal of High Resolution Chromatography, vol. 19, pp. $85-90$. 


\section{HNF-29820 Rev. 0}

\section{Appendix A: Estimates of $11.7 \mathrm{eV}$ Correction Factors}

The compounds 1,1-dichloroethane, dioxane, ethyl ether, and 1,2,4-trimethylbenzene do not have $11.7 \mathrm{eV}$ correction factors listed in RAE Systems, Inc., 2006. This appendix provides a rationale for the estimates of the $11.7 \mathrm{eV}$ correction factors listed for those compounds in Table 2. The correction factors discussed in this appendix are for an isobutylene-calibrated PID.

\section{A.1 Correction Factor Estimate for 1,1-Dichloroethane}

The correction factor for 1,1-dichloroethane is estimated to be less than that for methylene chloride: $<0.89$. This estimate is based on the observation that correction factors tend to decrease with increasing length of the carbon chain in a homologous series (RAE Systems, Inc. 2006).

\section{A.2 Correction Factor Estimate for 1,2,4-Trimethylbenzene}

RAE Systems, Inc., 2006, lists a correction factor of 0.3 for 1,3,5-trimethylbenzene (mesitylene). Because the two compounds are isomers of each other, the estimated correction factor for 1,2,4-trimethylbenzene is 0.3 .

\section{A.3 Correction Factor Estimates for Dioxane and Ethyl Ether}

RAE Systems, Inc., 2006, lists correction factors for a number of ethers for both $10.6 \mathrm{eV}$ and 11.7 eV PIDs; these are listed in Table A.1.

The data for the first six compounds in Table A.1 were least-squares fit to a line with the $10.6 \mathrm{eV}$ correction factors as the $\mathrm{x}$ data and the $11.7 \mathrm{eV}$ correction factors as the $\mathrm{y}$ data. The results of the least-squares fit are:

$$
11.7 \mathrm{eV} \text { correction factor }=0.8045 \times(10.6 \mathrm{eV} \text { correction factor })-0.0262
$$

The square of the correlation coefficient $\left(\mathrm{R}^{2}\right)$ for the least-squares fit is 0.9956 . Figure A.1 is a graph of the data and associated fitted line.

Inserting the respective $10.6 \mathrm{eV}$ correction factors for ethyl ether and dioxane from Table A.1 into the regression equation yields estimated $11.7 \mathrm{eV}$ correction factors of 0.86 for ethyl ether and 1.02 for dioxane. 
HNF-29820 Rev. 0

Table A.1 Correction Factors for Ethers for $10.6 \mathrm{eV}$ and $11.7 \mathrm{eV}$ PIDs

\begin{tabular}{|c|c|c|c|}
\hline Compound & $10.6 \mathrm{eV} \mathrm{CF}^{1}$ & $11.7 \mathrm{eV} \mathrm{CF}^{1}$ & $\begin{array}{c}\text { Estimated } \\
11.7 \mathrm{eV} \mathrm{CF}^{2}\end{array}$ \\
\hline ethylene glycol dimethyl ether & 0.86 & 0.7 & 0.67 \\
\hline 2-methoxyethoxyethanol & 1.2 & 0.9 & 0.94 \\
\hline 2-methoxyethyl ether & 0.54 & 0.44 & 0.41 \\
\hline methyl ether & 3.1 & 2.5 & 2.47 \\
\hline methoxy-2-propanol & 1.5 & 1.1 & 1.18 \\
\hline propylene glycol methyl ether & 1 & 0.8 & 0.78 \\
\hline ethyl ether & 1.1 & $\mathrm{n} / \mathrm{a}$ & 0.86 \\
\hline 1,4-dioxane & 1.3 & $\mathrm{n} / \mathrm{a}$ & 1.02 \\
\hline
\end{tabular}

Notes:

' Source: RAE Systems Inc. 2006.

${ }^{2}$ Estimated using the least-squares fit line:

$11.7 \mathrm{eV}$ correction factor $=0.8045 \times(10.6 \mathrm{eV}$ correction factor $)-0.0262$

$\mathrm{CF}=$ correction factor

$\mathrm{eV}=$ electron volt

$\mathrm{n} / \mathrm{a}=$ not available

PID = photoionization detector 


\section{HNF-29820 Rev. 0}

Figure A.1 Correction Factor Correlation for Ethers

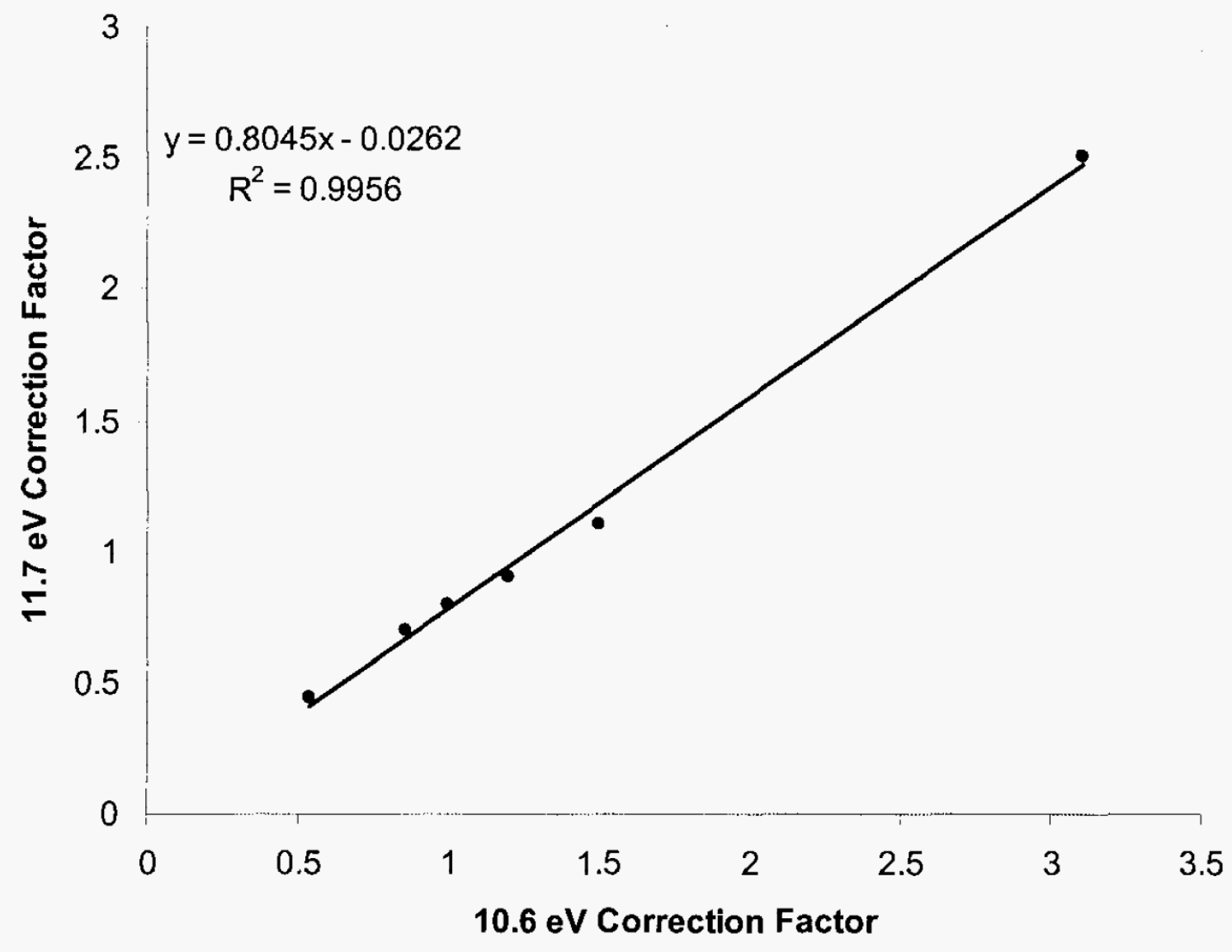

